\title{
N110
}

\section{Tailoring physical functionalities of complex oxides by vertically aligned nanocomposite thin-film design}

\author{
Jijie Huang, ${ }^{*}$ Weiwei Li, ${ }^{\star}$ Hao Yang, ${ }^{*}$ and Judith L. MacManus-Driscoll ${ }^{\star}$
}

\begin{abstract}
Self-assembled nanocomposite thin films couple two materials into a single film, typically, in the form of vertically aligned nanopillars embedded in a matrix film. High-density vertical heterointerfaces provide a great platform for engineering new physical properties and novel multifunctionalities, as well as for nanoscale device integration. Tremendous research efforts have been devoted to developing different nanocomposite systems. In this article, we summarize recent progress on vertically aligned nanocomposite thin films for enhanced functionalities such as ferroelectricity, tunable magnetoresistance, multiferroicity, dielectricity, magnetic anisotropy, perpendicular exchange bias, novel electrical/ionic properties, interfacial conduction, and resistive switching. Using specific examples, we discuss how and why the fundamental physical properties can be significantly tuned/improved in vertically aligned nanocomposites. Finally, we propose future research directions to achieve further enhanced performance as well as practical devices.
\end{abstract}

\section{Introduction}

Complex oxide thin films have been integrated into semiconductor devices, and oxide thin films are also of interest for many other wide-ranging electronic devices. ${ }^{1-5}$ The physical properties of oxide thin films can be tailored by film-substrateinduced biaxial strain effect, ${ }^{6-10}$ as well as doping effects. ${ }^{11-15}$ Over the past decade, tremendous research efforts and studies have been devoted to the development of heteroepitaxial oxide nanocomposite thin films, which involve co-growth of two oxide materials into one solid thin film. By careful materials selection (phase $A$ and phase $B$ ), a unique nanostructure of nanopillars (A phase) embedded in a film matrix (B phase) can be achieved (Figure 1), the so-called vertically aligned nanocomposite (VAN) thin films.

VAN thin films present multiple advantages over conventional plain oxide thin films, owing to their unique threedimensional (3D) strain states, a large number of vertical heterointerfaces, and also arising from the strong interplay of strain, spin, charge, and orbital orders both within the film and at interfaces. ${ }^{16,17}$ In plain oxide thin films epitaxially grown on single-crystal substrates, the physical properties can be tuned by the lattice mismatch strain between the film and the substrate (in-plane biaxial strain). However, the strain relaxes within a few tens of nanometers. On the other hand, in VAN thin films, apart from the film/substrate interface in the horizontal direction, the vertical heterointerfaces formed between phase A and phase B provide an out-of-plane strain, which dominates over the in-plane strain after only around a few nanometers film thickness. ${ }^{18}$ The independent out-of-plane strain can be retained throughout the whole film with thicknesses up to micrometer level, which is important for many device applications, and it is not realized in plain thin films or superlattices. Second, two-phase VAN films present multifunctionalities in various forms by a combination of (anti-) ferroelectric, (anti-)ferromagnetic, superconducting, conductive, or dielectric materials. For example, multiferroics have been achieved in VANs with coupled ferroelectric and ferromagnetic phase, such as $\mathrm{BaTiO}_{3}(\mathrm{BTO}): \mathrm{CoFe}_{2} \mathrm{O}_{4}(\mathrm{CFO}),{ }^{19}$ $\mathrm{BFO}: \mathrm{CFO},{ }^{20}$ and $\mathrm{BTO}: \mathrm{YMnO}_{3} \cdot{ }^{21}$ Furthermore, epitaxial growth of large lattice-mismatched or different crystal-structured VAN films can be realized by choosing an appropriate second phase. ${ }^{22-24}$ Also, new physical phenomenon or new phases can be induced by strain at the vertical heterointerface, which provides a great platform of new materials discovery.

Jijie Huang, School of Materials, Sun Yat-Sen University, Guangzhou, China; huangjj83@mail.sysu.edu.cn

Weiwei Li, College of Science, Nanjing University of Aeronautics and Astronautics, Nanjing, China; and Department of Materials Science and Metallurgy, University of Cambridge, Cambridge, UK; wl337@cam.ac.uk

Hao Yang, College of Science, Nanjing University of Aeronautics and Astronautics, Nanjing, China; yanghao@nuaa.edu.cn

Judith L. MacManus-Driscoll, Department of Materials Science and Metallurgy, University of Cambridge, Cambridge, UK; jld35@cam.ac.uk

${ }^{*}$ Corresponding author

doi:10.1557/s43577-021-00028-0 
A large number of material combinations have been explored in VANs, including oxide-oxide, ${ }^{19-24}$ oxidemetal, ${ }^{25-29}$ and nitride-metal. ${ }^{30-32}$ All oxides VAN thin films have been summarized in several topical reviews in different aspects, including growth mechanism, ${ }^{33}$ self-assembled ordering of phases, ${ }^{34}$ vertical strain control, ${ }^{35-39}$ device-design, ${ }^{40}$ and strain-defect-interface-function correlation. ${ }^{41}$

In this article, we will mainly focus on the functionalities of VAN films, as shown in Figure 1, including enhanced ferroelectricity, tunable magnetoresistance (MR), multiferroic, perpendicular exchange bias (PEB), magnetic anisotropy, novel ionic property, dielectricity, interface conduction, and resistive switching. We include only some exemplar works demonstrating enhanced and tunable properties of the aforementioned functionalities. Discussion and examples will be given in each section. We also give a perspective on the design of nanocomposite thin films for desirable functionalities, such as 3D nanocomposite thin films, as well as oxide-metal and nitride-metal nanocomposite thin films.

\section{Enhanced ferroelectricity}

Ferroelectric materials possess a spontaneous electric polarization and such polarization can be reversed by applying an external electric field. ${ }^{42,43}$ Strain engineering of ferroelectric thin films has been employed to improve its Curie temperature $\left(T_{\mathrm{C}}\right)$ and polarization; however, the substrateinduced biaxial strain is limited to the critical thickness. ${ }^{44}$ High strain states can be retained in thick VAN films using vertical lattice strain coupling of two epitaxial phases with different lattice constants and elastic moduli. ${ }^{45}$

Various VAN systems with ferroelectric phase have been fabricated to improve ferroelectricity. For example, low dielectric loss and enhanced dielectric tunability and ferroelectricity were realized in $\mathrm{Ba}_{0.6} \mathrm{Sr}_{0.4} \mathrm{TiO}_{3}(\mathrm{BSTO})_{1-x}:(\mathrm{SmO})_{x}$ system. ${ }^{46}$ Reduced dielectric loss and leakage current were reported in BFO:SmO system. ${ }^{47-49}$ Enhanced polarization and dielectric constant were reported in BTO:NiO system. ${ }^{50}$ Reduced leakage current and enhanced $T_{\mathrm{C}}$ were observed in BTO: $\mathrm{Sm}_{2} \mathrm{O}_{3}$ system. ${ }^{51-57}$ Vertical strain has also driven the hidden phase transition in $\mathrm{EuTiO}_{3}: \mathrm{MgO}$ syetem, ${ }^{58}$ and new ferroelectric phase formation in paraelectric $\mathrm{SrTiO}_{3}$ in $\mathrm{SrTiO}_{3}: \mathrm{MgO} .{ }^{59,60}$

Lee et al. investigated (BSTO) $)_{1-x}:\left(\mathrm{Sm}_{2} \mathrm{O}_{3}\right)_{x}(x=0,0.25,0.5$, $0.75)$ VAN films and found that strong tetragonal distortion induced a large ca. Value of 1.033 was obtained with $x=0.75$ film in a thick film of $1000 \mathrm{~nm}$ (Figure 2a). ${ }^{46}$ Also, it shows a large remanence polarization $\left(P_{\mathrm{r}}\right)$ value of $13.2 \mu \mathrm{C} \mathrm{cm}^{-2}$ (Figure $2 \mathrm{~b}$ ), which is $3 \times$ higher than that of the pure BSTO film with the same thickness (inset of Figure 2). Furthermore, $P_{\mathrm{r}}$ decays less rapidly with temperature with increasing $x$, indicating the effectiveness of vertical strain on improving the ferroelectric behavior (Figure $2 \mathrm{c}$ ). The $\mathrm{Pb}$-free films show better properties than the industry standard PZT.

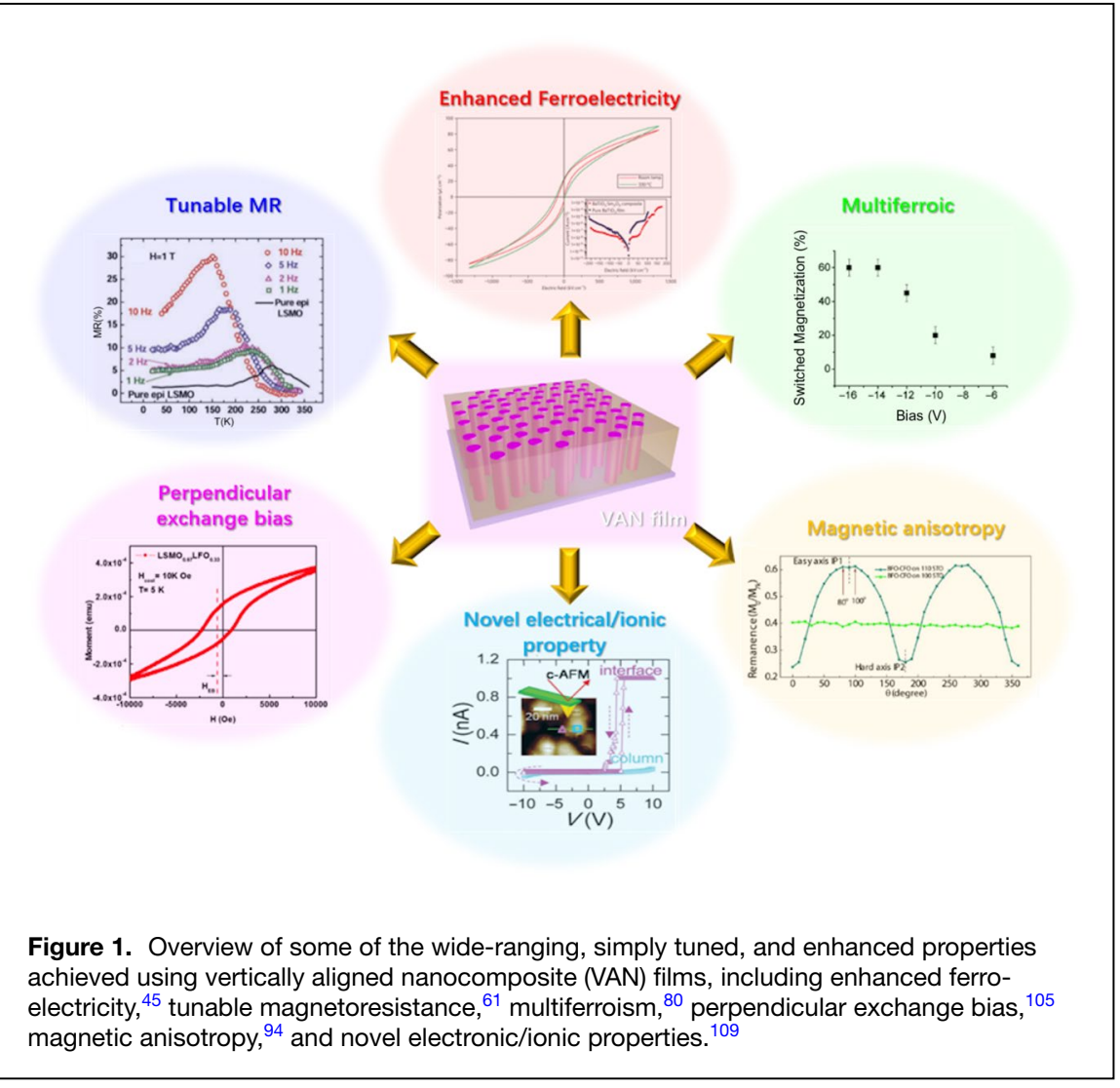

Tunable magnetoresistance Magnetoresistance (MR) is a physical property of electrical resistance change under an applied magnetic field. Introducing a secondary phase in a VAN thin-film matrix serves as an effective way to precisely tune the MR effect, as more phase/ grain boundaries are generated for spin-polarized tunneling/scattering. Three approaches have been demonstrated to tune the MR value in VAN thin films (Figure 3).

The first is incorporating different secondary phases (left panel in Figure 3). Taking $\mathrm{La}_{1-x} \mathrm{Sr}_{x} \mathrm{MnO}_{3}$ (LSMO) as an example, various secondary phases have been used in LSMO-based VAN films, to give the following compositions: LSMO:ZnO, ${ }^{61,62}$ LSMO: $\mathrm{CeO}_{2},{ }^{63,64}$ LSMO:MgO, ${ }^{65,66} \mathrm{LSMO} \mathrm{SrTiO}_{3}$ (STO), ${ }^{67}$ LSMO:CuO, ${ }^{68}$ and LSMO: $\mathrm{CoFe}_{2} \mathrm{O}_{4}$ (CFO). ${ }^{69}$

The second is varying the ratio of phases in the VAN films (middle 


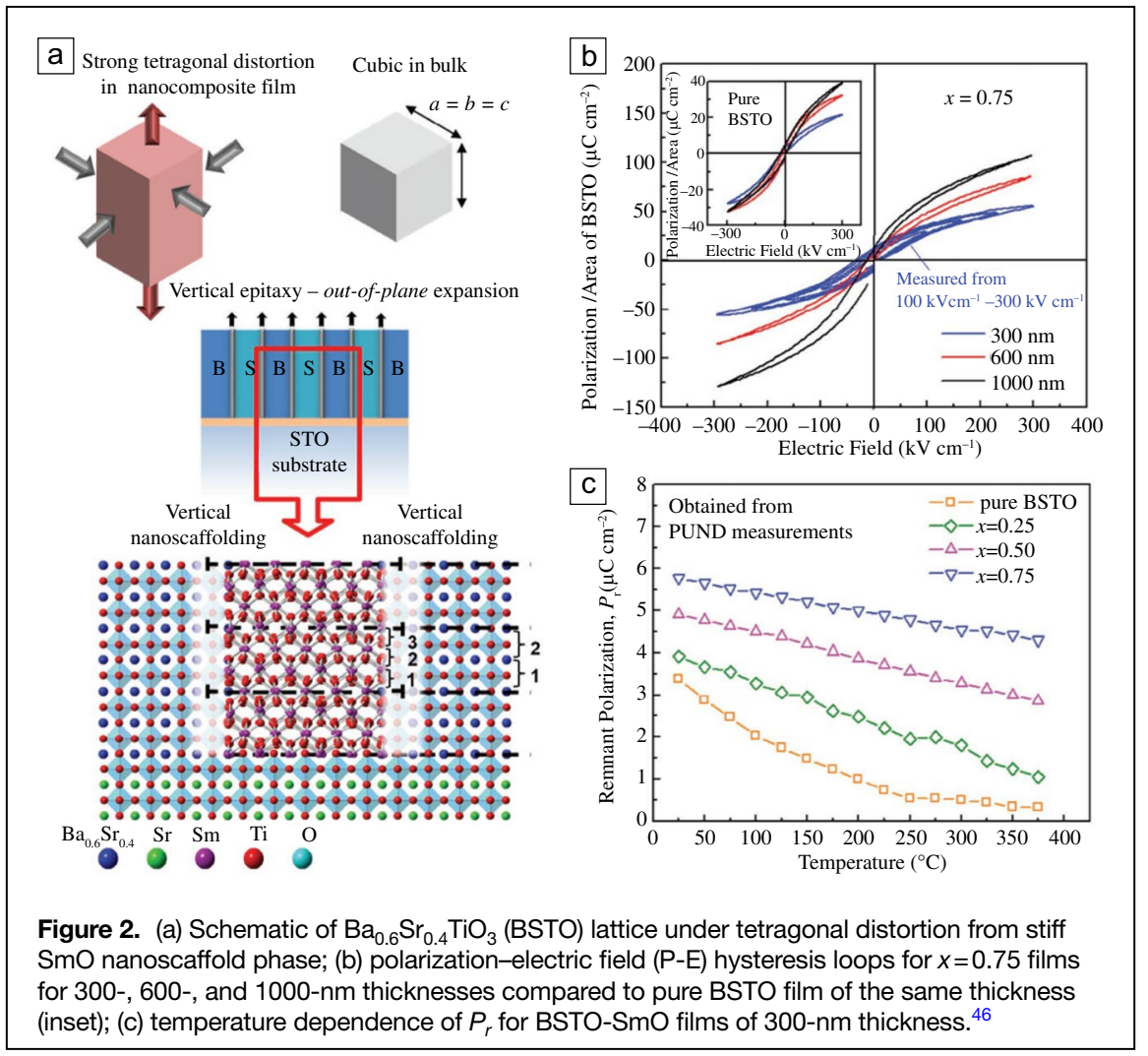

properties. Multiple nanocomposite systems with varying composition have been explored to develop the optimal composition, including (LSMO) ${ }_{1-x}$ $:(\mathrm{ZnO})_{x},{ }^{70,71}(\mathrm{LSMO})_{1-x}:\left(\mathrm{CeO}_{2}\right)_{x},{ }^{72}$ $\left(\mathrm{La}_{0.7} \mathrm{Ca}_{0.3} \mathrm{MnO}_{3}\right)_{1-x}:\left(\mathrm{CeO}_{2}\right)_{x},{ }^{73}$ and $\left(\mathrm{Pr}_{0.5} \mathrm{Ba}_{0.5} \mathrm{MnO}_{3}\right)_{1-x}:\left(\mathrm{CeO}_{2}\right)_{x}{ }^{74}$

Third is a $3 \mathrm{D}$ nanocomposite design in which superlattice and VAN structures are combined together (right panel in Figure 3). This approach gives a further tuning on strain engineering, allowing in-plane and outof-plane to be strained simultaneously. Such 3D nanocomposite design has been successfully realized in LSMO: $\mathrm{CeO}_{2} / \mathrm{CeO}_{2}$ or LSMO: $\mathrm{CeO}_{2} /$ LSMO, ${ }^{75}$ LSMO:ZnO/ZnO, ${ }^{76}$ and LSMO:MgO/LSMO. ${ }^{77}$ This enables precision tuning of MR values.

\section{Multiferroic}

Multiferroic materials with both ferroelectric and (anti)ferromagnetic properties are important not only for the multiple-degrees of freedom they possess, which are beneficial

panel in Figure 3). This influences the microstructural form (for low volume fractions of second-phase particles can form instead of rods, and it is also possible to move from rod/matrix to matrix/rod configuration), crystallinity, density of interfaces between phases, and overall strain in the film. These different parameters lead to a remarkable ability to tune physical for multistate memory, ${ }^{78}$ but also because of the coupling between two degrees of freedom which make it possible to control magnetism with an electric field, or vice versa. ${ }^{79}$ However, high-performance single-phase multiferroic materials do not exist; thus, the concept of nanocomposite thin-film coupling ferro-/ferrimagnetic and ferroelectric materials has




potential for forming artificial multiferroics. BFO:CFO is one of the most studied systems, which has been reproduced by multiple research groups. ${ }^{80-84}$ In addition to the conventional co-growth by single composite target or dual-growth by two single-phase targets, several nanofabrication procedures have been developed to obtain templated BFO:CFO VAN thin films. Aimon et al. successfully used focused ion beam (FIB) patterning combined with acid etching to create nanopatterns of 80-nm period, and then the deposited CFO and BFO formed an ordered and uniform BFO:CFO VAN nanostructure (method I in Figure 4a) ${ }^{82}$ Additionally, mask patterning (method II in Figure $4 b)^{83}$ and e-beam patterning combined with physical etch (method III in Figure $4 c)^{84}$ methods have also been developed to fabricate patterned BFO:CFO VAN films. Artificial multiferroics have been demonstrated in $\mathrm{BTO}: \mathrm{CFO},{ }^{85}$ $\mathrm{Fe}_{3} \mathrm{O}_{4}: \mathrm{BFO},{ }^{86} \mathrm{Bi}_{5} \mathrm{Ti}_{3} \mathrm{FeO}_{15}: \mathrm{CFO},{ }^{87} \mathrm{CFO}: \mathrm{PbTiO}_{3},{ }^{88}$ BTO: $\mathrm{YMnO}_{3},{ }^{21} \mathrm{CFO}: \mathrm{Bi}_{2} \mathrm{WO}_{6},{ }^{89}$ and $\mathrm{SmMnO}_{3}:(\mathrm{Bi}, \mathrm{Sm})_{2} \mathrm{O}_{3} \cdot{ }^{90}$ While the self-assembled, strained heterointerfaces in these VAN systems make them attractive for realizing the electric field switching of magnetism at room temperature, ${ }^{91}$ a key challenge is leakage both within the film and at the interfaces, both which hamper the ability to give electric field control of magnetism at room temperature (and above). Recent approaches (e.g., using the $\mathrm{Na}_{0.5} \mathrm{Bi}_{0.5} \mathrm{TiO}_{3}$ :CFO system) ${ }^{92}$ have demonstrated how to successfully address this challenge.

\section{Perpendicular magnetic anisotropy and perpendicular exchange bias}

Achieving perpendicular magnetic anistropy (PMA) in thin films is important for achieving high magnetic storage densities. ${ }^{93}$ In VAN films, the shape anisotropy form the anisotropic physical nature of magnetic pillars producing large PMA. ${ }^{94}$ Metal-oxide VAN films of $\mathrm{Fe}-\mathrm{LaSrFeO}_{4}$ (LSFO) (shown in Figure 5a) were demonstrated some time ago. Here, chemical decomposition of the complex oxide parent film under high vacuum growth conditions produced $\mathrm{Fe}$ nanopillars in an oxide matrix. ${ }^{95}$ A strong PMA was induced (Figure $5 \mathrm{~b}$ ), owing to the large aspect ratio of the Fe nanopillars. Recently, in situ growth of metal-oxide VAN films have been achieved simply from single composite targets or alternate deposition of metal and oxide targets (e.g., $\mathrm{Co}, \mathrm{Ni}$, or $\mathrm{CoNi}$ nanopillars), giving moderate magnetic anisotropy caused by the anisotropic nature of the metal nanopillars..$^{25,27,28,96,97}$ Magnetic anisotropy has also been realized in all-oxide VAN systems. In VAN systems such as BTO:CFO, ${ }^{19}$ LSMO:NiO, ${ }^{98}$ and LSMO:MgO, ${ }^{67}$ vertical strain effect dominates over shape anisotropy effect and PMA is mainly determined by the vertical strain. Recent smallangle neutron scattering results have uncovered that the CFO nanopillars with PMA in BTO-CFO VANs exhibit a core-shell magnetic structure. ${ }^{99}$ The magnetization initially reorients within the pillar core, followed by that of the shell. Magnetization nonuniformity on nanometer length scales is probably due to the strain relaxation along the radical direction. In fact, the critical thickness along the radical direction in both film matrix and pillars have rarely been discussed and such an effect on functionalities is largely unknown. ${ }^{41}$

Perpendicular exchange bias (PEB) has attracted enormous attention in recent years because of the tolerance of elements in spintronic devices to be reduced to the nanoscale, giving the possibility of higher density information storage/manipulation. PEB has been widely studied in metallic systems (often containing precious metals), ${ }^{100-102}$ but less so in cost-effective oxides with their wide range of compositions and functionalities. Notable examples of oxide VAN for PEB include LSMO/ $\mathrm{NiO}$ (Figure 5c). ${ }^{98}$ Here, there is coupling between ferromagnetic (FM) LSMO and antiferromagnetic (AFM) $\mathrm{NiO}$ along the 


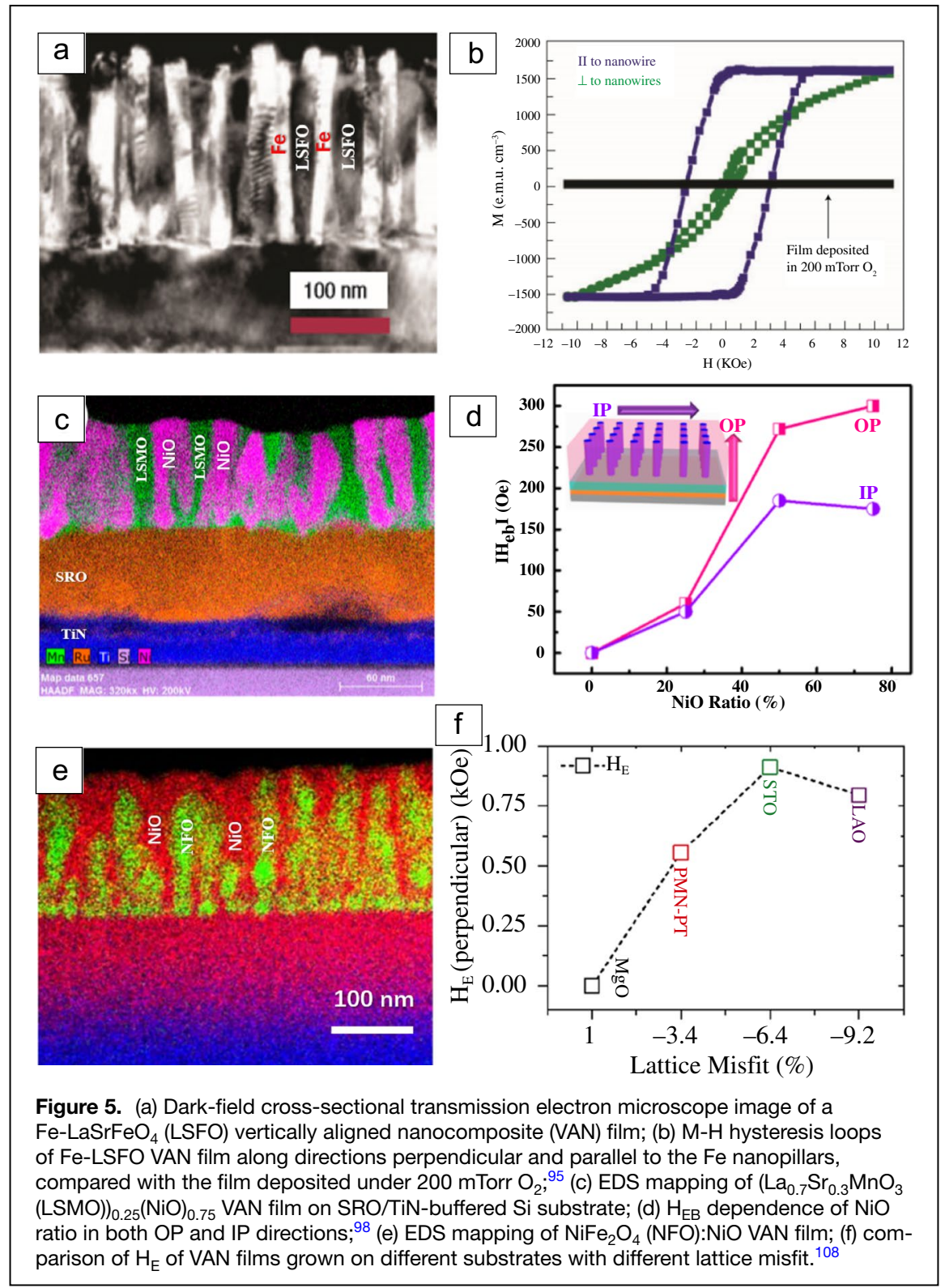

vertical interfaces. In addition, the PEB field $\left(\mathrm{H}_{\mathrm{E}}\right)$ could be controlled by the $\mathrm{NiO}$ fraction in the film (Figure $5 \mathrm{~d}$ ). Similar PEB has also been reported by FM-AFM VAN films of

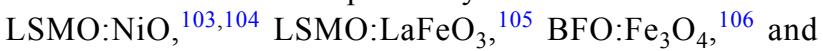
LSMO:BFO. ${ }^{107}$ Recently, by avoiding use of perovskites for the magnetic phase to reduce overall leakage and by carefully manipulating the FM/AFM via strain from the substrate, a $3 \times$ larger PEB of $0.91 \mathrm{kOe}$ was obtained at room temperature in $\mathrm{NiFe}_{2} \mathrm{O}_{4}$ : NiO VAN films (Figure 5e-f). ${ }^{108}$

\section{Novel electric/ionic properties}

One of the leading technologies for future power generation and also for electrolysis is the solid-oxide fuel cell (SOFC) or solid-oxide electrolytic cell (SOEC). One important challenge in improving $\mathrm{SO}(\mathrm{E}) \mathrm{FC}$ technology is to reduce the working temperature to below $\sim 500^{\circ} \mathrm{C}$. In the past decades, developing new electrolyte materials with high ionic conductivity has been a primary activity. VAN films have been developed to improve the ionic conductivity and design state-ofthe-art ionic devices. ${ }^{109}$ Compared to the oxygen ion diffusion along the lateral interface direction in the heterostructures, VANs allow fast oxygen ion transport along either vertical heterointerfaces or the nanocolumns which are the favored ion flow direction (Figure 6a). ${ }^{110}$ For the same film growth rates, the vertical ionic conductivity in $\left(\mathrm{Y}_{2} \mathrm{O}_{3}\right)_{0.08}\left(\mathrm{ZrO}_{2}\right)_{0.92}$ : $\mathrm{STO}$ (YSZ:STO) VAN films compared to plain YSZ films was increased by more than an order of magnitude by improving the crystallinity of YSZ nanocolumns via strain uniformity (Figure 6a). ${ }^{23,24}$ Similar observations were also reported in STO:SDC (Sm-doped $\left.\mathrm{CeO}_{2}\right)^{22,111}$ and YSZ:GDC (Gd-doped $\left.\mathrm{CeO}_{2}\right)^{112}$ VAN films. VAN films have also been used to enhance the slow oxygen reduction reaction (in most cases, the limiting bottleneck to reducing operations temperatures) at the cathodes in SOFCs. Oxygen reduction kinetics at $\left(\mathrm{La}_{1-x} \mathrm{Sr}_{x}\right)$ $\mathrm{CoO}_{3}:\left(\mathrm{La}_{1-x} \mathrm{Sr}_{x}\right)_{2} \mathrm{CoO}_{4}$ VAN cathodes showed approximately a tenfold enhancement compared to the respective single phases of either $\left(\mathrm{La}_{1-x} \mathrm{Sr}_{x}\right) \mathrm{CoO}_{3}$ or $\left(\mathrm{La}_{1-x} \mathrm{Sr}_{x}\right)_{2} \mathrm{CoO}_{4}$ (Figure 6b). ${ }^{113}$ This was attributed to enhanced electron availability for charge transfer and the suppression of detrimental cation segregation. In addition, the vertical interface of VANs was found to be more conductive than both phases, because of the additional $V_{\mathrm{O}}$ accumulated in the vertical interface regime. ${ }^{16,114}$

\section{Summary and future perspective}

We have provided a short overview of the status of selfassembled VAN thin films, focusing on exemplars which demonstrate precision tuning and enhancement of properties. Overall, the unique and easy-to-make nanostructure of vertically aligned nanopillars embedded in an epitaxial matrix provides great possibility in materials design, and the engineering of new and improved physical phenomena resulting from 


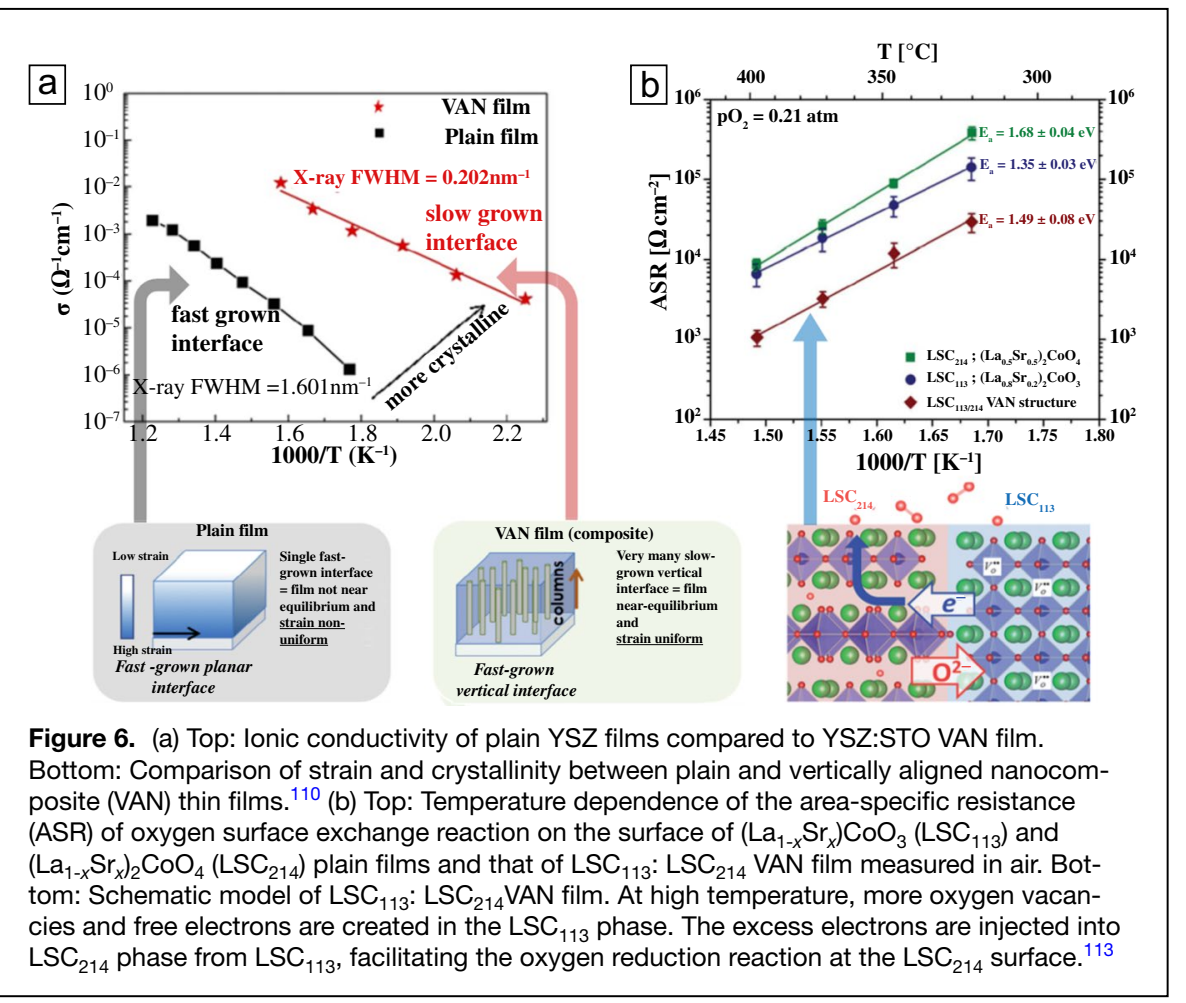

Third, metal-oxide nanocomposite designs should be further explored (e.g., for achieving novel plasmonic effects, which are more rare in oxide compositions). ${ }^{26,29,131,132}$ Fourth, nonoxide VANs should be explored (e.g., with nitride ${ }^{30-32,133}$ and carbide compositions). These nonoxides are also highly amenable to sputtering, which is beneficial for industrial applications (see last point next). Fifth, since spatial ordering is highly demanded for future nanoscale device integration, further work needs to be done in this regard. While pioneering work has been committed to tedious nanofabrication ${ }^{82-84}$ and substrate pretreatment, ${ }^{134}$ further efforts should be devoted to the discovery of simple and universal methods to obtain ordered nanopillars. Early work here shows some promise. ${ }^{34}$ Sixth, strain engineering in $3 \mathrm{D} \mathrm{VANs}^{75-77,135}$

the formation of anisotropic nanopillar geometries, as well as the high density of clean vertical heterointerfaces which enable unique strain and coupling effects. In addition to the functionalities highlighted in this article, we note that VAN thin films can also be applied to engineer properties in many other functional systems (e.g., increasing $T_{\mathrm{C}}{ }^{115,116}$ and pinning in superconducting thin films, ${ }^{117-122}$ room temperature metal-insulator transitions, ${ }^{123}$ enhanced ferrimagnetism, ${ }^{124}$ induced ferromagnetic-insulating behavior, ${ }^{125,126}$ as well as improved resistive switching performance). ${ }^{127,128}$ There is still a large space for further exploration.

First, for all-oxides VANs, only a small fraction of possible compositions have been explored for desirable functionalities. ${ }^{129,130}$ Hence there is much scope to explore nonperovskite systems (e.g., Ruddlesden Poppers, pyrocholores, fluorites, and bixbyites) combined with a wide range of binary oxide compositions and structures where there are scores of systems which have not been studied. In terms of choosing the correct materials from a vast number, the approach should be first to decide on the functional property or property enhancement being sought and then the selection of the appropriate materials (in terms of chemical compatibility, individual functionalities, and possibility to combine functionalities). Second, new physics of the vertical heterointerfaces should be explored using surface probes. The fact that interfaces intersect the film surfaces is extremely beneficial for enabling easy access to study interface properties and for providing understanding of two-phase coupling effects. ${ }^{116}$ could be applied much more widely to new systems to achieve physical property enhancements.

Two final important points for industry application need to be addressed more fully. The first is growth of films on silicon. There are good examples of success here, ${ }^{57,70,98,136,137}$ but more work should be demonstrated for the wide applicability to many VAN systems. The second is using more cost-effective, large-area scale-up deposition methods. To date, more VAN films have mostly been deposited by pulsed laser deposition. However, sputtering, electron-beam evaporation, or metal organic chemical vapor deposition would be more appropriate methods. While some works have shown the promise of sputtering for oxide VAN, ${ }^{138,139}$ more work is still needed to demonstrate the universality of this and other large-area methods.

\section{Acknowledgments}

J.H. acknowledges the support from the Guangdong Basic and Applied Basic Research Foundation (2019A1515111029) and the Fundamental Research Funds for the Central Universities (20lgpy13). W.-W.L. and J.L.M.-D. acknowledge support from EPSRC Grants EP/N004272/1. J.L.M.-D. also acknowledges support from the Royal Academy of Engineering, Grant No. CiET1819 24, EPSRC Grant Nos. EP/L011700/1, EP/ P007767/1, EP/T012218/1, the ERC POC Grant No. 779444 (Portapower), and the Isaac Newton Trust (Minute 13.38(k)). H.Y. acknowledges support from the National Natural Science Foundation of China (Grant No. 11774172). 


\section{Open Access}

This article is licensed under a Creative Commons Attribution 4.0 International License, which permits use, sharing, adaptation, distribution and reproduction in any medium or format, as long as you give appropriate credit to the original author(s) and the source, provide a link to the Creative Commons licence, and indicate if changes were made. The images or other third party material in this article are included in the article's Creative Commons licence, unless indicated otherwise in a credit line to the material. If material is not included in the article's Creative Commons licence and your intended use is not permitted by statutory regulation or exceeds the permitted use, you will need to obtain permission directly from the copyright holder. To view a copy of this licence, visit http://creativecommons.org/licenses/by/4.0/.

\section{References}

1. E. Fortunato, P. Barquinha, R. Martins, Adv. Mater. 24, 2945 (2012)

2. C.H. Ahn, K.M. Rabe, J.M. Triscone, Science 303(5657), 488 (2004)

3. Ü. Özgür, Y.I. Alivov, C. Liu, A. Teke, M.A. Reshchikov, S. Doğan, V. Avrutin, S.-J. Cho, H. Morkoç, J. Appl. Phys. 98, 041301 (2005)

4. A. Jiang, C. Wang, K. Jin, X. Liu, J.F. Scott, C. Hwang, T. Tang, H. Lu, G. Yang, Adv. Mater. 23, 1277 (2011)

5. L.W. Martin, Y.H. Chu, R. Ramesh, Mater. Sci. Eng. R Rep. 68, 89 (2010)

6. K.M. Rabe, Curr. Opin. Solid State Mater. Sci. 9, 122 (2005)

7. J.P. Locquet, J. Perret, J. Fompeyrine, E. Machler, J.W. Seo, G. Van Tendelo0, Nature 394, 453 (1998)

8. D.G. Schlom, L.Q. Chen, C.B. Eom, K.M. Rabe, S.K. Streiffer, J.M. Triscone, Ann. Rev. Mater. Res. 37, 589 (2007)

9. S.J. May, J.W. Kim, J.M. Rondinelli, E. Karapetrova, N.A. Spaldin, A. Bhattacharya, P.J. Ryan, Phys. Rev. B 82, 014110 (2010)

10. M.W. Chu, I. Szafraniak, R. Scholz, C. Harnagea, D. Hesse, M. Alexe, U. Gösele, Nat. Mater. 3, 87 (2004)

11. A. Tsukazaki, A. Ohtomo, T. Onuma, M. Ohtani, T. Makino, M. Sumiya, K. Ohtani, S.F. Chichibu, S. Fuke, Y. Segawa, H. Ohno, H. Koinuma, M. Kawasaki, Nat. Mater. 4, 42 (2005)

12. S. Ohta, T. Nomura, Appl. Phys. Lett. 87, 092108 (2005)

13. J. Huang, H. Wang, X. Sun, X. Zhang, H. Wang, ACS Appl. Mater. Interfaces 10, 42698 (2018)

14. S. Chambers, Adv. Mater. 22, 219 (2010)

15. H. Kimura, Appl. Phys. Lett. 80, 94 (2002)

16. Y. Hsieh, E. Strelcov, J. Liou, C. Shen, Y. Chen, S.V. Kalinin, Y. Chu, ACS Nano 7, 8627 (2013)

17. J. Mannhart, D.G. Schlom, Science 327, 1607 (2010)

18. J.L. MacManus-Driscoll, P. Zerrer, H. Wang, H. Yang, J. Yoon, A. Fouchet, R. Yu, M.G. Blamire, Q. Jia, Nat. Mater. 7, 314 (2008)

19. H. Zheng, J. Wang, S.E. Lofland, Z. Ma, L. Mohaddes-Ardabili, T. Zhao, L. Salamanca-Riba, S.R. Shinde, S.B. Ogale, F. Bai, D. Viehland, Y. Jia, D.G. Schlom, M. Wuttig, A. Roytburd, R. Ramesh, Science 303, 661 (2004)

20. D.H. Kim, N.M. Aimon, X.Y. Sun, L. Kornblum, F.J. Walker, C.H. Ahn, C.A. Ross, Adv. Funct. Mater. 24, 5889 (2014)

21. X. Gao, L. Li, J. Jian, H. Wang, M. Fan, J. Huang, X. Wang, H. Wang, ACS Appl. Nano Mater. 1, 2509 (2018)

22. S.M. Yang, S.B. Lee, J. Jian, W. Zhang, Q.X. Jia, H. Wang, T.W. Noh, S.V. Kalinin, J.L. MacManus-Driscoll, Nat. Commun. 6, 8588 (2015)

23. S. Lee, J.L. MacManus-Driscoll, APL Mater. 5, 042304 (2017)

24. S. Lee, W. Zhang, F. Khatkhatay, H. Wang, Q. Jia, J.L. MacManusDriscoll, Nano Lett. 15, 7362 (2015)

25. J. Huang, L. Li, P. Lu, Z. Qi, X. Sun, X. Zhang, H. Wang, Nanoscale $\mathbf{9}$, 7970 (2017)
26. L. Li, L. Sun, J.S. Gomez-Diaz, N.L. Hogan, P. Lu, F. Khatkhatay, W. Zhang, J. Jian, J. Huang, Q. Su, M. Fan, C. Jacob, J. Li, X. Zhang, Q. Jia, M. Sheldon, A. Alú, X. Li, H. Wang, Nano Lett. 16, 3936 (2016)

27. J. Huang, Z. Qi, L. Li, H. Wang, S. Xue, B. Zhang, X. Zhang, H. Wang, Nanoscale 10, 17182 (2018)

28. F.J. Bonilla, A. Novikova, F. Vidal, Y. Zheng, E. Fonda, D. Demaille, V. Schuler, A. Coati, A. Vlad, Y. Garreau, M.S. Simkin, Y. Dumont, S. Hidki, V. Etgens, ACS Nano 7, 4022 (2013)

29. J. Huang, X. Wang, X.L. Phuah, P. Lu, Z. Qi, H. Wang, Mater. Today Nano 8, 100052 (2019)

30. X. Wang, J. Jian, Z. Zhou, C. Fan, Y. Dai, L. Li, J. Huang, J. Sun, A. Donohue, P. Bermel, X. Zhang, H. Chen, H. Wang, Adv. Opt. Mater. 7, 1801180 (2019)

31. J. Huang, X. Wang, N.L. Hogan, S. Wu, P. Lu, Z. Fan, Y. Dai, B. Zeng, R. Starko-Bowes, J. Jian, H. Wang, L. Li, R.P. Prasankumar, D. Yarotski, M. Sheldon, H. Chen, Z. Jacob, X. Zhang, H. Wang, Adv. Sci. 6, 1800416 (2018)

32. X. Wang, J. Jian, S. Diaz Amaya, C.E. Kumah, P. Lu, J. Huang, D.G. Lim, V. Pol, J. Youngblood, A. Boltasseva, L. Stanciu, D. O'Carroll, X. Zhang, H. Wang, Nanoscale Adv. 1, 1045 (2018)

33. J.L. MacManus-Driscoll, Adv. Funct. Mater. 20, 2035 (2010)

34. X. Sun, J.L. MacManus-Driscoll, H. Wang, Ann. Rev. Mater. Res. 50, $229(2020)$

35. J. Huang, J.L. MacManus-Driscoll, H. Wang, J. Mater. Res. 32(21), 4054 (2017)

36. A. Chen, Z. Bi, Q. Jia, J.L. MacManus-Driscoll, H. Wang, Acta Mater. 61, 2783 (2013)

37. W. Zhang, A. Chen, Z. Bi, Q. Jia, J.L. MacManus-Driscoll, H. Wang, Curr. Opin. Solid State Mater. Sci. 18, 6 (2014)

38. J.L. MacManus-Driscoll, A. Suwardi, H. Wang, MRS Bull. 40, 933 (2015)

39. J.L. MacManus-Driscoll, A. Suwardi, A. Kursumovic, Z. Bi, C. Tsai, H. Wang, Q. Jia, 0. Lee, APL Mater. 3, 062507 (2015)

40. W. Zhang, R. Ramesh, J.L. MacManus-Driscoll, H. Wang, MRS Bull. 40, 736 (2015)

41. A. Chen, Q. Su, H. Han, E. Enriquez, Q.X. Jia, Adv. Mater. 31, 1803241 (2019)

42. G.H. Haertling, J. Am. Ceram. Soc. 82, 797 (1999)

43. Y. Zhang, M. Xie, V. Adamaki, H. Khanbareh, C.R. Bowen, Chem. Soc. Rev. 46(24), 7757 (2017)

44. K.J. Choi, M. Biegalski, Y.L. Li, A. Sharan, J. Schubert, R. Uecker, P. Reiche, Y.B. Chen, X.Q. Pan, V. Gopalan, L.Q. Chen, D.G. Schlom, C.B. Eom, Science 306, 1005 (2004)

45. S.A. Harrington, J. Zhai, S. Denev, V. Gopalan, H. Wang, Z. Bi, S.A.T. Redfern, S. Baek, C.W. Bark, C. Eom, Q. Jia, M.E. Vickers, J.L. MacManus-Driscoll, Nat. Nanotech. 6, 491 (2011)

46. 0. Lee, A. Kursumovic, Z. Bi, C. Tsai, H. Wang, J.L. MacManusDriscoll, Adv. Mater. Interfaces 4, 1700336 (2017)

47. O. Lee, S.A. Harrington, A. Kursumovic, E. Defay, H. Wang, Z. Bi, C. Tsai, L. Yan, Q. Jia, J.L. MacManus-Driscoll, Nano Lett. 12, 4311 (2012)

48. H. Yang, H. Wang, J. Yoon, Y. Wang, M. Jain, D.M. Feldmann, P.C. Dowden, J.L. MacManus-Driscoll, Q. Jia, Adv. Mater. 21, 3794 (2009)

49. R. Zhao, W. Li, A. Chen, W. Zhang, J. Yang, Y. Liang, R. Tang, H. Wang, H. Yang, Appl. Phys. Lett. 105, 072907 (2014)

50. M.J. Chen, X.K. Ning, S.F. Wang, G.S. Fu, RSC Adv. 7, 38231 (2017)

51. A. Kursumovic, E. Defay, O. Lee, C. Tsai, Z. Bi, H. Wang, J.L. MacManus-Driscoll, Adv. Funct. Mater. 23, 5881 (2013)

52. A.L. Sangle, O. Lee, A. Kursumovic, W. Zhang, A. Chen, H. Wang, J.L. MacManus-Driscoll, Nanoscale 10, 3460 (2018)

53. W. Li, R. Zhao, R. Tang, A. Chen, W. Zhang, X. Lu, H. Wang, H. Yang, ACS Appl. Mater. Interfaces 6, 5356 (2014)

54. W. Li, W. Zhang, L. Wang, J. Gu, A. Chen, R. Zhao, Y. Liang, H. Guo, R. Tang, C. Wang, K. Jin, H. Wang, H. Yang, Sci. Rep. 5, 11335 (2015) 
55. X. Zhang, R. Xu, X. Gao, Y. Ji, F. Qian, J. Fan, H. Wang, W. Li, H. Yang, J. Mater. Chem. C 8, 8091 (2020)

56. X. Zhang, R. Xu, X. Gao, M. Li, X. Shi, Y. Ji, F. Qian, J. Fan, H. Wang, W. Li, H. Yang, Appl. Surf. Sci. 516, 146093 (2020)

57. F. Khatkhatay, A. Chen, J.H. Lee, W. Zhang, H. Abdel-Raziq, H. Wang, ACS Appl. Mater. Interfaces 5, 12541 (2013)

58. R. Zhao, Y. Chen, Y. Ji, W. Li, L. Chen, A. He, H. Lu, M. Zhao, J. Yao, Y. Jiang, G. Liu, J. Gao, H. Wang, H. Yang, Appl. Phys. Lett. 114, 252901 (2019)

59. S. Singh, A. Laxman Sangle, T. Wu, N. Khare, J.L. MacManusDriscoll, ACS Appl. Mater. Interfaces 11, 45683 (2019)

60. E. Enriquez, Q. Li, P. Bowlan, P. Lu, B. Zhang, L. Li, H. Wang, A.J. Taylor, D. Yarotski, R.P. Prasankumar, S.V. Kalinin, Q.X. Jia, A. Chen, Nanoscale 12, 18193 (2020)

61. A. Chen, Z. Bi, C. Tsai, J. Lee, Q. Su, X. Zhang, Q. Jia, J.L. MacManus-Driscoll, H. Wang, Adv. Funct. Mater. 21, 2423 (2011)

62. A. Chen, M. Weigand, Z. Bi, W. Zhang, X. Lu, P. Dowden, J.L. MacManus-Driscoll, H. Wang, Q. Jia, Sci. Rep. 4, 5426 (2014)

63. L. Balcells, A.E. Carrillo, B. Martínez, J. Fontcuberta, Appl. Phys. Lett. 74, 4014 (1999)

64. A. Chen, Z. Bi, H. Hazariwala, X. Zhang, Q. Su, L. Chen, Q. Jia, J.L. MacManus-Driscoll, H. Wang, Nanotechnology 22, 315712 (2011)

65. A. Chen, J. Hu, P. Lu, T. Yang, W. Zhang, L. Li, T. Ahmed, E. Enriquez, M. Weigand, Q. Su, H. Wang, J. Zhu, J.L. MacManus-Driscoll, L. Chen, D. Yarotski, Q. Jia, Sci. Adv. 2, e1600245 (2016)

66. M. Staruch, D. Hires, A.P. Chen, Z. Bi, H. Wang, M. Jain, J. Appl. Phys. 110, 113913 (2011)

67. S.A. Koster, V. Moshnyaga, K. Samwer, O.I. Lebedev, G. van Tendeloo, 0. Shapoval, A. Belenchuk, Appl. Phys. Lett. 81, 1648 (2002)

68. M. Fan, H. Wang, S. Misra, B. Zhang, Z. Qi, X. Sun, J. Huang, H. Wang, ACS Appl. Mater. Interfaces 10, 5779 (2018)

69. 0.I. Lebedev, J. Verbeeck, G. Van Tendeloo, 0. Shapoval, A. Belenchuk, V. Moshnyaga, B. Damashcke, K. Samwer, Phys. Rev. B 66, 104421 (2002)

70. W. Zhang, A. Chen, F. Khatkhatay, C. Tsai, Q. Su, L. Jiao, X. Zhang, H. Wang, ACS Appl. Mater. Interfaces 5, 3995 (2013)

71. A. Chen, W. Zhang, F. Khatkhatay, Q. Su, C. Tsai, L. Chen, Q.X. Jia, J.L. MacManus-Driscoll, H. Wang, Appl. Phys. Lett. 102, 093114 (2013)

72. M. Fan, W. Zhang, F. Khatkhatay, L. Li, H. Wang, J. Appl. Phys. 118, 065302 (2015)

73. X. Gao, L. Li, J. Jian, J. Huang, X. Sun, D. Zhang, H. Wang, Appl. Phys. Lett. 115, 053103 (2019)

74. S. Cheng, L. Shen, C. Ma, S. Cheng, Y. Dai, S. Mi, M. Liu, C. Jia, CrystEngComm 20, 5017 (2018)

75. X. Sun, J. Huang, J. Jian, M. Fan, H. Wang, Q. Li, J.L. MacManusDriscoll, P. Lu, X. Zhang, H. Wang, Mater. Horiz. 5, 536 (2018)

76. X. Sun, Q. Li, J. Huang, J. Jian, P. Lu, X. Zhang, J.L. MacManusDriscoll, H. Wang, J. Appl. Phys. 125, 082530 (2019)

77. A. Chen, Z. Harrell, P. Lu, E. Enriquez, L. Li, B. Zhang, P. Dowden, C. Chen, H. Wang, J.L. MacManus-Driscoll, Q. Jia, Adv. Funct. Mater. 29, 1900442 (2019)

78. W. Huang, W. Zhao, Z. Luo, Y. Yin, Y. Lin, C. Hou, B. Tian, C. Duan, X. Li, Adv. Electron. Mater. 4, 1700560 (2018)

79. R. Ramesh, N.A. Spaldin, Nat. Mater. 6, 21 (2007)

80. F. Zavaliche, T. Zhao, H. Zheng, F. Straub, M.P. Cruz, P.L. Yang, D. Hao, R. Ramesh, Nano Lett. 7, 1586 (2007)

81. W. Zhang, M. Fan, L. Li, A. Chen, Q. Su, Q. Jia, J.L. MacManus-Driscoll, H. Wang, Appl. Phys. Lett. 107, 212901 (2015)

82. N.M. Aimon, H.K. Choi, X. Sun, D.H. Kim, C.A. Ross, Adv. Mater. 26 , 3063 (2014)

83. S.M. Stratulat, X. Lu, A. Morelli, D. Hesse, W. Erfurth, M. Alexe, Nano Lett. 13, 3884 (2013)

84. R. Comes, H. Liu, M. Khokhlov, R. Kasica, J. Lu, S.A. Wolf, Nano Lett. 12, 2367 (2012)
85. A. Chen, Y. Dai, A. Eshghinejad, Z. Liu, Z. Wang, J. Bowlan, E. Knall, L. Civale, J.L. MacManus-Driscoll, A.J. Taylor, R.P. Prasankumar, T. Lookman, J. Li, D. Yarotski, Q.X. Jia, Adv. Sci. 6, 1901000 (2019)

86. E. Weal, S. Patnaik, Z. Bi, H. Wang, T. Fix, A. Kursumovic, J.L. MacManus Driscoll, Appl. Phys. Lett. 97, 153121 (2010)

87. A. Imai, X. Cheng, H.L. Xin, E.A. Eliseev, A.N. Morozovska, S.V. Kalinin, R. Takahashi, M. Lippmaa, Y. Matsumoto, V. Nagarajan, ACS Nano 7, 11079 (2013)

88. I. Levina, J. Slutsker, J. Li, Z. Tan, A.L. Roytburd, Appl. Phys. Lett. 91, $062912(2007)$

89. H. Wang, L. Li, J. Huang, X. Gao, X. Sun, H. Wang, Mater. Res. Lett. 7, $418(2019)$

90. E. Choi, T. Maity, A. Kursumovic, P. Lu, Z. Bi, S. Yu, Y. Park, B. Zhu, R. Wu, V. Gopalan, H. Wang, J.L. MacManus-Driscoll, Nat. Commun. 11, 2207 (2020)

91. T. Fix, E. Choi, J.W.A. Robinson, S.B. Lee, A. Chen, B. Prasad, H. Wang, M.G. Blamire, J.L. MacManus-Driscoll, Nano Lett. 13, 5886 (2013)

92. R. Wu, A. Kursumovic, X. Gao, C. Yun, M.E. Vickers, H. Wang, S. Cho, J.L. MacManus-Driscoll, ACS Appl. Mater. Interfaces 10, 18237 (2018)

93. P.F. Carcia, A.D. Meinhaldt, A. Suna, Appl. Phys. Lett. 47, 178 (1985)

94. Z. Wang, Y. Li, R. Viswan, B. Hu, V.G. Harris, J. Li, D. Viehland, ACS Nano 7, 3447 (2013)

95. L. Mohaddes-Ardabili, H. Zheng, S.B. Ogale, B. Hannoyer, W. Tian, J. Wang, S.E. Lofland, S.R. Shinde, T. Zhao, Y. Jia, L. Salamanca-Riba, D.G. Schlom, M. Wuttig, R. Ramesh, Nat. Mater. 3, 533 (2004)

96. B. Zhang, J. Huang, J. Jian, B. Rutherford, L. Li, S. Misra, X. Sun, H. Wang, Nano. Adv. 1, 4450 (2019)

97. Q. Su, W. Zhang, P. Lu, S. Fang, F. Khatkhatay, J. Jian, L. Li, F. Chen, X. Zhang, J.L. MacManus-Driscoll, A. Chen, Q.X. Jia, H. Wang, ACS Appl. Mater. Interfaces 8, 20283 (2016)

98. J. Huang, A. Gellatly, A. Kauffmann, X. Sun, H. Wang, Cryst. Growth Des. 18, 4388 (2018)

99. T.0. Farmer, E. Guo, R.D. Desautels, L. DeBeer-Schmitt, A. Chen, Z. Wang, Q.X. Jia, J.A. Borchers, D.A. Gilbert, B. Holladay, S.K. Sinha, M.R. Fitzsimmons, Phys. Rev. Mater. 3, 081401(R) (2019)

100. S. Maat, K. Takano, S.S.P. Parkin, E.E. Fullerton, Phys. Rev. Lett. 87, 087202 (2001)

101. C.Y. Tsai, J. Hsu, K.F. Lin, J. Appl. Phys. 117, 17D153 (2015)

102. J.Y. Chen, N. Thiyagarajah, H.J. Xu, J.M.D. Coey, Appl. Phys. Lett. 104, 152405 (2014)

103. W. Zhang, L. Li, P. Lu, M. Fan, Q. Su, F. Khatkhatay, A. Chen, Q. Jia, X. Zhang, J.L. MacManus-Driscoll, H. Wang, ACS Appl. Mater. Interfaces 7, 21646 (2015)

104. J. Huang, H. Wang, X. Wang, X. Gao, J. Liu, H. Wang, ACS Appl. Mater. Interfaces 12, $39920(2020)$

105. M. Fan, W. Zhang, J. Jian, J. Huang, H. Wang, APL Mater. 4, 076105 (2016)

106. E. Choi, E. Weal, Z. Bi, H. Wang, A. Kursumovic, T. Fix, M.G. Blamire, J.L. MacManus-Driscoll, Appl. Phys. Lett. 102, 012905 (2013)

107. W. Zhang, A. Chen, J. Jian, Y. Zhu, L. Chen, P. Lu, Q. Jia, J.L. MacManus-Driscoll, X. Zhang, H. Wang, Nanoscale 7, 13808 (2015)

108. R. Wu, C. Yun, X. Wang, P. Lu, W. Li, Y. Lin, E. Choi, H. Wang, J.L. MacManus-Driscoll, ACS Appl. Mater. Interfaces 10, 42593 (2018)

109. S. Lee, A. Sangle, P. Lu, A. Chen, W. Zhang, J. Lee, H. Wang, Q. Jia, J.L. MacManus-Driscoll, Adv. Mater. 26, 6284 (2014)

110. J.L. MacManus-Driscoll, M.P. Wells, C. Yun, J. Lee, C. Eom, D.G. SchIom, APL Mater. 8, 40904 (2020)

111. B. Zhu, G. Schusteritsch, P. Lu, J.L. MacManus-Driscoll, C.J. Pickard, APL Mater. 7, 061105 (2019)

112. Q. Su, D. Yoon, A. Chen, F. Khatkhatay, A. Manthiram, H. Wang, J. Power Sources 242, 455 (2013)

113. W. Ma, J. Kim, N. Tsvetkov, T. Daio, Y. Kuru, Z. Cai, Y. Chen, K. Sasaki, H.L. Tuller, B. Yildiz, J. Mater. Chem. A 3, 207 (2015) 
114. Y. Zhao, J. Li, Z. Yin, X. Zhang, J. Huang, L. Cao, H. Wang, J. Alloys Compd. 823, 153699 (2020)

115. E. Choi, A.D. Bernardo, B. Zhu, P. Lu, H. Alpern, K.H.L. Zhang, T. Shapira, J. Feighan, X. Sun, J. Robinson, Y. Paltiel, O. Millo, H. Wang, Q. Jia, J.L. MacManus-Driscoll, Sci. Adv. 5, eaav5532 (2019)

116. E. Choi, B. Zhu, P. Lu, J. Feighan, X. Sun, H. Wang, J.L. MacManusDriscoll, Nanoscale 12, 3157 (2020)

117. J. Huang, M. Fan, H. Wang, L. Chen, C. Tsai, L. Li, H. Wang, Ceram. Int. 42, $12202(2016)$

118. R. Zhao, W. Li, J.H. Lee, E.M. Choi, Y. Liang, W. Zhang, R. Yang, H. Wang, Q. Jia, J.L. MacManus-Driscoll, H. Yang, Adv. Funct. Mater. 24, 5240 (2014)

119. J.L. MacManus-Driscoll, S.R. Foltyn, Q.X. Jia, H. Wang, A. Serquis, L. Civale, B. Maiorov, M.E. Hawley, M.P. Maley, D.E. Peterson, Nat. Mater. 3, 439 (2004)

120. J. Huang, C. Tsai, L. Chen, J. Jian, F. Khatkhatay, K. Yu, H. Wang, J. Appl. Phys. 115, 123902 (2014)

121. W. Li, L. Wang, R. Zhao, R. Tang, Y. Liang, H. Yang, J. Appl. Phys. 116, 183904 (2014)

122. G. Celentano, F. Rizzo, A. Augieri, A. Mancini, V. Pinto, A. Rufoloni, A. Vannozzi, J.L. MacManus-Driscoll, J. Feighan, A. Kursumovic, A. Meledin, J. Mayer, G. Van Tendeloo, Supercond. Sci. Technol. 33, 044010 (2020)

123. W. Chang, H. Liu, V. Tra, J. Chen, T. Wei, W.Y. Tzeng, Y. Zhu, X. Kuo, Y. Hsieh, J. Lin, Q. Zhan, C. Luo, J. Lin, J. He, C. Wu, Y. Chu, ACS Nano 8, 6242 (2014)

124. C. Park, R. Wu, P. Lu, H. Zhao, J. Yang, B. Zhang, W. Li, C. Yun, H. Wang, J.L. MacManus-Driscoll, S. Cho, Adv. Funct. Mater. 28, 1706220 (2018)

125. C. Yun, E. Choi, W. Li, X. Sun, T. Maity, R. Wu, J. Jian, S. Xue, S. Cho, H. Wang, J.L. MacManus-Driscoll, Nanoscale 12, 9255 (2020)

126. Y. Lin, E. Choi, P. Lu, X. Sun, R. Wu, C. Yun, B. Zhu, H. Wang, W. Li, T. Maity, J.L. MacManus-Driscoll, ACS Appl. Mater. Interfaces 12, 8513 (2020)

127. L. Li, L. Lu, Z. Wang, Y. Li, Y. Yao, D. Zhang, G. Yang, J. Yao, D. Viehland, Y. Yang, Sci. Rep. 5, 9229 (2015)

128. S. Cho, C. Yun, S. Tappertzhofen, A. Kursumovic, S. Lee, P. Lu, Q. Jia, M. Fan, J. Jian, H. Wang, S. Hofmann, J.L. MacManus-Driscoll, Nat. Commun. 7, 12373 (2016)

129. J. Huang, H. Wang, D. Li, Z. Qi, D. Zhang, P. Lu, H. Chen, D.A. Yarotski, P. Lin, X. Zhang, H. Wang, ACS Appl. Mater. Interfaces 12, 23076 (2020)

130. F. Wang, C. Jiang, J. Huang, Appl. Phys. Lett. 117, 162902 (2020)

131. J. Huang, T. Jin, S. Misra, H. Wang, Z. Qi, Y. Dai, X. Sun, L. Li, J. Okkema, H. Chen, P. Lin, X. Zhang, H. Wang, Adv. Opt. Mater. 6, 1800510 (2018)

132. F. Wang, J. Huang, Ceram. Int. 46, 25817 (2020)

133. J. Huang, X. Wang, D. Li, T. Jin, P. Lu, D. Zhang, P. Lin, H. Chen, J. Narayan, X. Zhang, H. Wang, Adv. Mater. Interfaces 7, 2000493 (2020)

134. M. Fan, B. Zhang, H. Wang, J. Jian, X. Sun, J. Huang, L. Li, X. Zhang, H. Wang, Adv. Mater. 29, 1606861 (2017)

135. X. Sun, Q. Li, J. Huang, M. Fan, B.X. Rutherford, R.L. Paldi, J. Jian, X. Zhang, H. Wang, Appl. Mater. Today 16, 204 (2019)

136. M. Kalaswad, D. Zhang, X. Gao, L.L. Contreras, H. Wang, X. Wang, H. Wang, ACS Appl. Mater. Interfaces 11, 45199 (2019)

137. M. Kalaswad, B. Zhang, X. Wang, H. Wang, X. Gao, H. Wang, Nanoscale Adv. 2, 4172 (2020)

138. T. Kim, S. Ojha, G. Tian, S. Lee, H. Jung, J. Choi, L. Kornblum, F.J. Walker, C.H. Ahn, C.A. Ross, D. Kim, J. Mater. Chem. C 6, 5552 (2018)

139. J. Gao, X. Wu, Q. Li, S. Du, F. Huang, L. Liang, H. Zhang, F. Zhuge, Hz. Cao, Y. Song, Adv. Mater. 29, 1605324 (2017)



Jijie Huang is an associate professor in the School of Materials at Sun Yat-sen University, China. He received his PhD degree from Texas A\&M University in 2016, and then completed postdoctoral research at Purdue University. His current research focuses on the growth and characterization of functional oxide and nanocomposite thin films. Huang can be reached by email at huangjj83@mail.sysu.edu.cn.

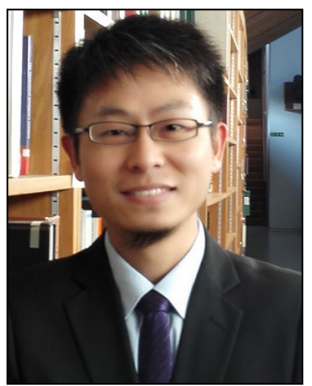

Weiwei Li is a professor of aeronautics and astronautics in the College of Science at Nanjing University, China. He received his $\mathrm{PhD}$ degree from Soochow University, China, in 2015. He is a fellow of the University of Cambridge, UK, where he was a research associate. His current research interests focus on the synthesis and properties of complex metal-oxide thin films and heterostructures relevant to application for (opto-)electronic devices, and energy conversion/storage. Li can be reached by email atw1337@cam.ac.uk.

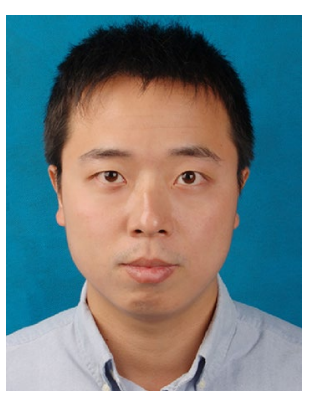

Hao Yang is a professor in the College of Science at Nanjing University of Aeronautics and Astronautics, China. His current research interests focus on functional oxide materials and physics, including ferroelectric, ferromagnetic, and multiferroic, relevant to the application for data storage and flexible sensors. Yang can be reached by email at yanghao@nuaa.edu.cn.

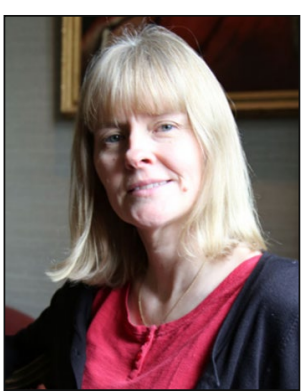

Judith Driscoll is a professor in materials science at the University of Cambridge, UK. Her current research focuses on oxide thin-film electronics. Driscoll can be reached by email at jld35@ cam.ac.uk. 